\title{
Labor transformation in insurance in the context of digitalization
}

\author{
Elena Karanina ${ }^{1, *}$, Dmitriy Tulenty ${ }^{2}$, and Marina Selivanova ${ }^{2}$ \\ ${ }^{1}$ Vyatka State University, Moskovskaya St., 36, Kirov, 610000, Russia \\ ${ }^{2}$ Financial University Of Goverment of the Russian Federation, Leningradsky Prospekt, 49, Moscow, \\ 125993, Russia
}

\begin{abstract}
The subject of research in the article is the transformation of labor and labor relations in modern insurance. This transformation is due to the transition to a new technological structure based on digitalization, as well as comprehensive informatization of all aspects of public life. The hypothesis that served as the impetus for writing this article is the provision that modern digitalization, unlike its previous automation and informatization, does not aim at increasing the productivity of human labor, but at completely eliminating a person from the production process. In the course of work on the article, the authors used materials from the largest recruiting agency HeadHunter, and also conducted their own research in the form of a survey of insurance market specialists on the issues of transforming labor relations and the demand for new competencies. As a result, it is shown that significant transformations occur both in the content of labor processes and in the competencies that employees should possess. The changes that are taking place impose new requirements on the quality of human capital, a new paradigm of human capital management is being approved, in which the employee is considered not only as an object, but also as an independent subject of management. The transformation of the basic factors (economic, technological, social) of labor relations in insurance is considered.
\end{abstract}

\section{Introduction}

First of all, a significant change in labor relations in insurance is due to the transition to a new technological structure (based on digitalization) and the information society. Now the technological structure is built on a new scientific and technological base, which significantly changes both the content of the labor process and the requirements for employees' competencies. The main source of increasing the insurers' productivity and increasing their competitiveness is human capital of a new quality.[1;2]. Quantum technologies, the growing role of critical thinking and erudition have led to such a phenomenon as digitalization.

The transformation of the labor market in the context of digitalization is the main challange, since increasing the efficiency of a particular employee will ultimately lead to

${ }^{*}$ Corresponding author: kafinanc@yandex.ru 
job cuts and an increase in the wage difference.

Digitalization changes the role of a man in the economic process, puts forward new requirements for competencies, their formation and development. The digital economy, both the scientific and the applied one, is still only an emerging and insufficiently investigated phenomenon. The digital economy is a set of relations that are formed in the processes of production / distribution / exchange / consumption based on digital technologies and lead to the emergence and adoption of new ways of managing [3].

According to the analysis of the digital economy evolution, its main principles are: enhancing consumer value; customization of products; reduction of horizontal relationships and transaction costs; use of "digital doubles"; ecosystem approach to the organization of economic activity [4].

The paradigm of personnel management is changing in the context of digitalization. Human resource management and human capital management are increasingly occupied with the concept of human management, which is considered not only as an object, but also as a subject of management [3]. The structural characteristics of the human factor in the new conditions mean the level of education; intelligence; professionalism; ongoing training and self-education; network literacy and advanced communication [5].

\section{Materials and methods}

Based on the data presented by one of the largest headhunting and employee search sites in the world, HeadHunter, we can show the dynamics of insurance sector vacancies in Russia and the Moscow region in 2019.

Table 1. Dynamics of insurance sector vacancies in Russia and the Moscow region in 2019 [6].

\begin{tabular}{|c|c|c|c|}
\hline Region & $\begin{array}{c}\text { Dynamics of } \\
\text { vacancies }\end{array}$ & $\begin{array}{c}\mathrm{CV} \\
\text { dynamics }\end{array}$ & Index \\
\hline All regions & $-11 \%$ & $9 \%$ & 1,6 \\
\hline The Moscow region & $-8 \%$ & $66 \%$ & 1,9 \\
\hline
\end{tabular}

The source: compiled by the authors based on the site Hh.ru

As can be seen from Table 1, there was a decrease in vacancies in the insurance market both in Russia in general (by $11 \%$ ) and in the Moscow region (by $8 \%$ ). The number of vacancies increased by $9 \%$ in Russia and by $66 \%$ in the Moscow region. The same trend is in the financial market. If to consider applicants in the insurance industry by gender, women take up the largest share (more than 61\%)

The transformation of labor relations in insurance is due to the introduction of modern high technology. Their important characteristics is resource saving, including labor saving. The transformation of labor relations in insurance is multidimensional and affects such areas as economics, law, sociology, psychology, etc. This transformation can be defined as the (controlled or uncontrolled) process of appearing new elements and characteristics of the labor relations system, in particular related to a change in its value and target parameters. These changes are primarily reflected in the following three subsystems: "technical and economic aspects - axiological aspects"; "technical and economic aspects institutional aspects" and "institutional aspects - axiological aspects". These changes occur in the following set of interdependent elements: labor processes - human capital institutions - values (motives). Moreover, a change in one element transforms the entire system. 
Let us examine how the transformation of basic factors (economic, technological, social ones) affects the main elements of the system of labor relations in insurance (institutional environment, labor processes, human capital, values and motivation).

Economic factors change the institutional aspects of labor relations in insurance (rules, norms, mechanisms for the implementation of labor relations). In particular, they change the nature of labor, its organization, which is characterized by complexity and multi-level approval of a new economic structure, the structure of value chains, lead to new forms of organization and remuneration. Moreover, economic factors change the structure of human capital, ways to attract and organize it.

Technological factors significantly change the content of labor activity in insurance. In particular, the introduction of the latest technologies in insurance lead to changes in the institutional framework of labor interactions and their regulation. Labor processes are transformed and creative, intellectual labor prevails. It leads to a new quality and new indicators of productivity and labor efficiency.

Social factors change institutional components that influence the level of inclusiveness and tolerance in labor relations. In modern conditions, there is an increase in the intellectualization of labor in insurance, changes in the structure of knowledge and professional competencies of employees.

The most demanded competencies in the context of digitalization along with the traditional ones are: analytical skills; work with large amounts of information; susceptibility to new technologies; multitasking; interdisciplinary knowledge [7].

The examples: Sberbank developed and introduced a new competency model that took into account the transition to a digital economy in 2016. Gazprom developed a model for the continuous development of competencies in 2017 [7].

Unlike the purposes of automation and informatization (to help a person solve production problems), digitalization is aimed to exclude a person from the production process. It has serious socio-economic consequences and threats. In the future, digitalization can lead to a significant reduction in physical jobs and the release of a large number of other kinds of jobs, which can become a serious problem. Some specialties may soon simply disappear. As for insurance sector, the use of cognitive technologies will exclude people involved in routine operations with documents, and in the near future, robotics will replace most employees of call centers and various control panels.

Many specialties will require significant transformations in order to maintain their workplace in a changing environment. The use of artificial intelligence and machine learning methods will lead to the fact that machines will increasingly begin to be embedded in the processes of assessing and accepting insurance risks and resolving losses. Insurers are increasingly relying on the multidisciplinary workers who are involved in the management of various automated processes in the field of underwriting. The prospect of robotic processes for signing insurance contracts casts doubt on the possibility of the existence of traditional insurance intermediaries, or will require a radical review of their role and functionality.

The complete or partial disappearance of some specialists from the insurance market will be accompanied by an increase in demand for specialists who are currently not trained. First of all, they are specialists who can develop ways to apply modern technologies in insurance, introduce these technologies and ensure their operation and improvement. The solution to this problem should be provided by representatives of universities and academic science, and by a system of professional retraining of the insurance community.

The following qualification requirements for employees of insurance organizations established by the All-Russian Union of Insurers in 2015 were:

Knowledge / Skills:

1. Experience in calculating insurance rates; knowledge of underwriting techniques. 
2. Knowledge of regulatory documents governing insurance activities in the Russian Federation.

Abilities / competencies:

1. Personal qualities: analytical mind, discipline, diligence, responsibility, kindness, punctuality.

2. PC knowledge: advanced user - MS Office 2010, Excel, 1C.

3. Ability to achieve significant results in a short time.

Attention is also paid to the employee's ability to think ahead, a high response rate in case of problems, the ability to effectively interact with colleagues, basic knowledge of using new technologies.

In 2019 the following points were added to the requirements of 2015:

- knowledge of technologies and skills for working with big data;

- skills to work with online services;

- basic knowledge in the field of insurance and actuarial activities;

- knowledge of the main trends in the development of the insurance market and the digital technology market;

- forecasting and modeling skills;

- real-time data analysis skills and the implementation of automated risk management;

- knowledge of organizational change management techniques;

- ability to predict customer needs and offer additional services.

Requirements for specialists in the insurance industry will be higher year by year, the employee's reaction rate will increase when making decisions. Employees of insurance organizations also need to have systemic and critical thinking, to be able to solve poorly structured tasks.

In such difficult conditions of the transformation of labor relations, special attention should be paid to stimulating employees. The leaders of insurance companies face the problem of assessing the employees who, due to changing conditions, are constantly changing their duties and requirements. Therefore, the company must constantly improve the skills of its employee. As a result, a company employee becomes an object of competition between employer companies, as he gets a set of skills and is ready to offer them to other companies.

The new technological structure suggests an increase in the share of creative intellectual work in comparison with routine technical operations. The classical model of full-time employment is increasingly replaced by remote employment and other unusual forms of employment: outsourcing, outstaffing, freelance, etc.

Retraining of personnel, especially of middle-aged people in the new conditions due to their age-specific nature, can lead to the situation when they start solving less qualified tasks and having a wage reduction. Moreover, highly qualified specialists may be in a worse situation than low-skilled ones, as the employer will strive to use their existing competencies as long as possible, they will be late to undergo professional retraining and, therefore, enter the labor market at a time when the positions adequate their status and competencies will already be occupied. All these processes can lead to an atmosphere of tension in the organization, which means less efficiency and labor productivity.

The transition to a new technological structure in the economy is accompanied by dramatic changes in communication technologies and the motivation of labor behavior. It will inevitably lead to significant changes in labor relations, their decentralization and distance. In addition, the widespread use of outsourcing and the development of communications will minimize the number of permanent office workers, and the size and number of offices. Structures working with a virtual office or locating offices in the regions with the lowest costs are likely to appear. The bulk of the staff will be temporary employees 
involved in the implementation of a specific project rather than permanent full-time employees.

\section{Results}

The transformation of labor relations in insurance leads to an increase in labor productivity, which is based both on a more efficient use of resources and on a new quality of communications [8].

The Program of Cooperation between Russia and the International Labor Organization for 2017-2020 emphasizes non-standard forms of labor relations, blurring the boundaries between work and leisure, taking into account the particularities in the preferences of generations $\mathrm{X}-\mathrm{Y}-\mathrm{Z}$. Transformation of labor relations emphasizes uncertainty and risk in the process of achieving the goal, creativity and the ability to adapt to changes play the main role here.

Considering the impact of digitalization on the labor market, we can distinguish the following consequences:

- differentiation and flexibility of labor market segments associated with scientific and technological progress;

- "non-standard" forms of employment;

- a new type of labor relationship, etc.

New forms of employment are highly unstable. In developed countries, the extent of unstable employment is significant. Therefore, a lot of research has been devoted to the study of this phenomenon in the sociology of labor and labor law [9]. In the context of changing labor relations, there is a new class - the precariat, where workers do not have permanent employment due to the employee's forced loss of standard labor relations.

Let us consider the share of the employed population of generation $\mathrm{Z}, \mathrm{Y}$ in the total structure of the employed population in Russia over the past few years. According to Fig. 1, about $50 \%$ of the total employed population of Russia are occupied by the Z, Y generations. Representatives of this group strive for high salaries; they are also eager to exchange their time for the absence or restriction of social relations, professional and intellectual creativity caused by employment at work [11].

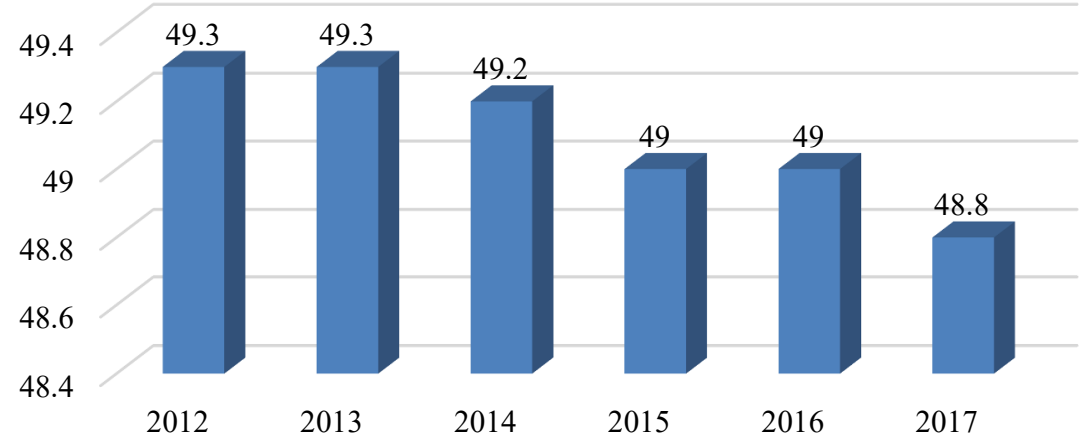

Fig. 1. Dynamics of the share of employed generation $\mathrm{Z}, \mathrm{Y}$ in the total structure of the employed population in Russia, 2012-2017, \%

Professor A.A. Fedchenko offers a scheme of the digitalization process influence on changing social and labor relations. It emphasizes that the digitalization of the economy is based on modern international and Russian legislative framework, which allows to expand employment opportunities and increase labor productivity when assessing the professional 
level of a specialist based on professional standards [12].

Professional standards form the labor demand and supply; there is close interaction with educational institutions.

In our opinion, the transformation of social and labor relations in modern conditions is connected with the development of new forms of labor relations; the appearance of representatives of generations $\mathrm{X}, \mathrm{Y}, \mathrm{Z}$ on the labor market; orientation of education to the labor market.

According to Fig. 2, the number of people aged 15-72 in financial and insurance activities has grown by 1.5 times over the 11 years. However, analyzing the changes in the number of specialists in the financial sector, we should note that the dynamics over the past 2-3 years indicates a decrease of this indicator. For example, the growth in the number of employees in 2017 compared to 2012 was $10 \%$, and in 2017 compared to 2016 only $1 \%$.

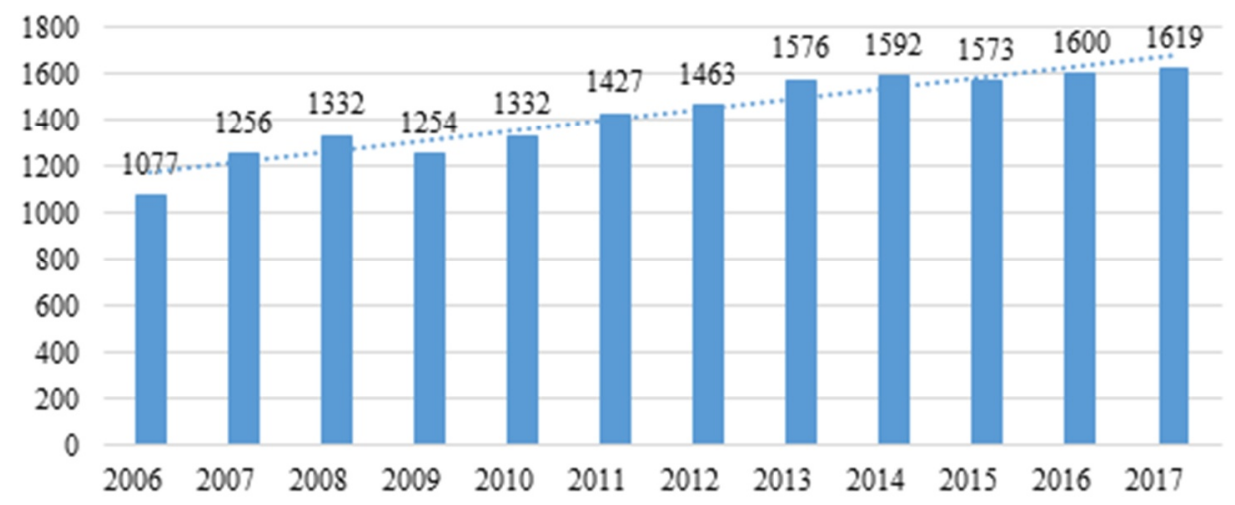

Fig. 2. Dynamics of the number of employees aged 15-72 in financial and insurance activities in Russia, 2006-2017, thousand people

Despite the expansion of the financial sector, digital technologies can restrain the growth in the number of personnel involved in this area.

Fig. 3 shows that the share of employed aged 15-72 remains unchanged over the past 5 years in financial and insurance activities.

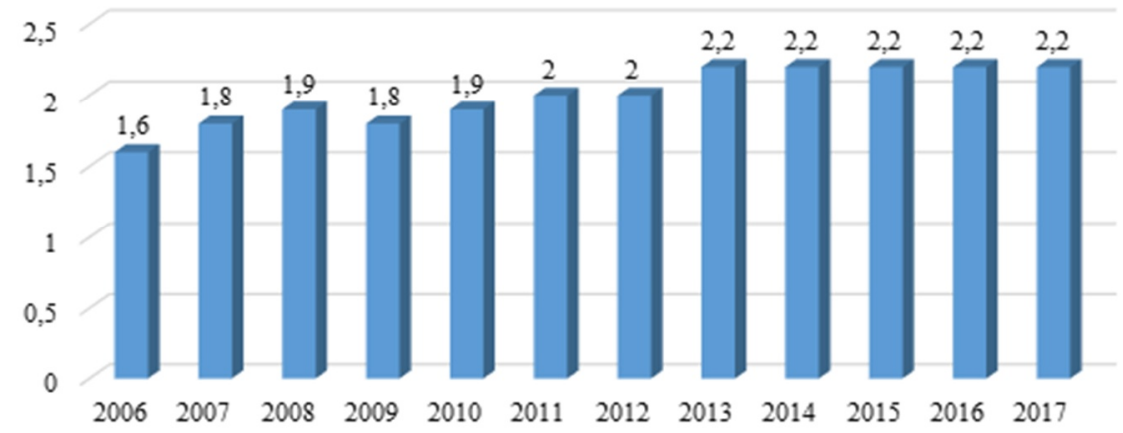

Fig. 3. Dynamics of the share of the number of employees aged 15-72 in financial and insurance activities, 2006-2017, thousand people

The change of generations of " $\mathrm{X}-\mathrm{Y}$ - Z" leads to the change in consumer demand and there is a need for digitalization [13], which fundamentally changes the traditional work of employees of insurance companies. A great role is given to building new business models, 
systems and programs that can satisfy customer requests in real time, optimizing resources, playing scenarios, calculating risks, reducing marketing costs, etc.

\section{Discussion}

The authors have conducted a survey among representatives of various Russian insurance organizations. Employees were asked to answer several questions:

1. What do you mean by digitalization of the insurance market?

2. What types of activities of the insurance organization, in your opinion, will be transformed primarily in connection with digitalization?

3. In your opinion, can the digitalization of insurance companies lead to the dismissal of employees?

4. Are you afraid of the fact that artificial intelligence will completely replace the employee of the insurance organization?

5. What competencies should an employee of a modern insurance organization have to be a demanded specialist in the insurance market despite its constant changes?

Employees of insurance companies understand the digitalization of the insurance market, as the automation of contracting and accounting, the inclusion of the insurance market in the general system of the digital economy, the use of digital technologies in insurance, possible digital risks and the need for their insurance.

According to the respondents, the main activities of the insurance organization, which will be transformed primarily, are interaction with customers, document management, risk assessment and underwriting, marketing. The Russian insurance market is very conservative, the introduction of new technologies began only 3 years ago, while abroad this area began to develop in 2012. World practice shows that medical and life insurance are types of insurance mostly affected by technology.

Insurers consider the introduction of chat bots, like in banking, digital speech technologies, mobile applications, big data analysis, the use of drones, etc. as a digitalization of the market.

According to respondents, the digitalization of insurance companies will not lead to the dismissal of employees. It is the opinion of more than $83 \%$ of respondents, $12 \%$ found it difficult to answer, $5 \%$ thought that it would lead to job cuts in the insurance market.

The statistics of answers of employees of insurance companies is almost the same: $86 \%$ believe that artificial intelligence can never replace an employee of an insurance organization, $10 \%$ see this as reality, $4 \%$ find it difficult to answer.

When asked what to do in order to be in demand in the insurance market, the respondents' answers were: to have competencies that allow working with databases, be able to apply new technologies to insurance business processes, know and be able to apply new financial technologies in insurance activities, constantly improve skills in accordance with changes in the market, be able to adapt to new conditions, etc.

\section{Conclusion}

The research allows to draw the following conclusions:

1. The use of innovative technologies such as cognitive technology; cloud technologies; big data technology; artificial intelligence will lead to a significant transformation of the insurance industry. Most of the functions of insurers will be performed either by machines without the participation of people, or transferred to outsourcing. The efforts of the insurers will mainly focus on finding and securing a place in the value chain and adapting to market conditions. The use of modern innovative technologies will lead to a significant expansion 
of the direct competitors of insurers. They will include: owners of digital platforms; manufacturers of substitutes and quasi-insurance products; $\mathrm{p} 2 \mathrm{p}$ and similar platforms; property park owners in a shared economy; Big Tech companies.

2. The use of innovative technologies will lead to a significant transformation of labor relations in insurance. The goal of digitalization is to exclude people from the production process. In this regard, many specialties demanded today will disappear or demand for them will significantly decrease. At the same time, there will be a demand for the currently missing specialties; the volatility of this demand can be very high.

The article was prepared based on the results of studies carried out at the expense of budget funds on the state order of the Financial University.

\section{References}

1. O.A. Alekseenko. Inform. Society, 2, 25-28 (2018) DOI: 10.2991/cssdre-19.2019.62

2. V.I. Ananyin, K.V. Zimin, Informatics, 2(44), 45-54 (2018) DOI: 10.17323/19980663.2018.2.45.54

3. Yu.A. Salikov, I.V. Logunova, Bulletin of the Voronezh State University of Engineering Technology, 81(2), 393-399 (2019) DOI: 10.20914/2310-1202-2019-2393-399

4. M. Kargalova,.Scientific and Analytical Herald of IE RAS, 1, 174-179 (2018) DOI: 10.15211/vestnikieran2201826

5. I.A. Kiseleva, N.E. Simonovich, et al. Bulletin of the Voronezh State University of Engineering Technology, 81(1), 402-411 (2019) DOI: 10.20914/2310-1202-2019-1402-411

6. HeadHunter (Access date: 19.02.2020) URL: stats.hh.ru/regioncomparison\#dateFrom=1\&dateTo=12\&profarea $\% 5 \mathrm{~B} \% 5 \mathrm{D}=19 \&$ region $\% 5 \mathrm{~B} \% 5 \mathrm{D}=113$

7. Yu.A. Salikov, I.V. Logunova et al. Bulletin of the Voronezh State University of Engineering Technology, 81(2), 393-399 (2019) DOI: 10.20914/2310-1202-2019-2393-399

8. . V.G. Lutchenko., A.I. Khorev et al. Bulletin of the Voronezh State University of Engineering Technology, 81(3), 368-374 (2019) DOI: 10.20914/2310-1202-2019-3368-374

9. J. Benach, A. Vives et al. Annual Review of Public Health, 35, 229-253 (2014) (Access date: 19.02.2020) URL: www.annualreviews.org/doi/full/10.1146/annurevpublhealth-032013-182500 (accessed date: $08 / 26 / 2019$ )

10. Federal State Statistics Service. (Access date: 17.02.2020) URL: www.gks.ru/free_doc/doc_2018/rab_sila18.pdf

11. E.Yu. Legchilina. Russian Journal of Labor Economics, 6(1) (2019) DOI: 10.18334/et.6.1.40493

12. A.A. Fedchenko, O.A. Kolesnikova et al. Digital Economy: Complexity and Variety vs. Rationality ISC 2019, 599-605 (2020) DOI: 10.1007/978-3-030-29586-8_69

13. A.A. Tsyganov, D.V. Bryzgalov. Economy. Taxes. Right, (2), 111-120 (2018) DOI: 10.26794/1999-849X-2018-11-2-111-120

14. S. Kalkavan, A. Katrinli et al. Social and Behavioral Sciences, 210, 241-250 (2015) DOI: $10.1016 /$ j.sbspro.2015.11.364 
15. O.M. Babanskaya, G. Mozhaeva et al. Feshchenko. Published, 8th international conference on education and new learning technologies (2016) DOI: 10.21125/EDULEARN.2016.2057

16. I. Malkova, O.M. Babanskaya et al. 12th international technology, education and development conference (2018) DOI: 10.21125/INTED.2018.1104 